\title{
A obra Admirável mundo novo no ensino interdisciplinar: fonte de reflexões sobre Ciência, Tecnologia e Sociedade
}

\author{
The Brave new world novel in the interdisciplinary teaching: \\ source of reflections on socioscientific issues
}

\author{
Andréa Carla de Souza Góes ${ }^{1}$ \\ https://orcid.org/0000-0001-5585-4546. \\ Danielle Cristina Duque Estrada Borim ${ }^{2}$ \\ https://orcid.org/0000-0002-1716-8809. \\ Daniel Kaufman ${ }^{1}$. Ana Carolina Clemente dos Santos ${ }^{1}$. \\ Andréa Espinola de Siqueira ${ }^{1}$. Magui Aparecida Vallim ${ }^{1}$
}

\begin{abstract}
Resumo: Discutimos o impacto da utilização da ficção científica, associada ao enfoque Ciência, Tecnologia e Sociedade (CTS), no desenvolvimento crítico dos alunos e o consequente despertar para o exercício da cidadania. Para tal, aplicamos uma sequência didática para alunos do ensino Médio, baseada na obra Admirável mundo novo, em uma perspectiva Freireana. A atividade é fundamentada na discussão, a partir de material de apoio preparado para os temas CTS destacados da obra: consumismo, uso de drogas, manipulação genética e exclusão social. A intervenção foi avaliada por meio de questionário. Verificamos o desenvolvimento do senso crítico dos alunos através das relações das temáticas CTS da sociedade contemporânea com a sociedade criada por Aldous Huxley em 1932. Os alunos perceberam a atividade como interdisciplinar, relacionando os temas abordados com várias disciplinas, e valorizaram a prática pedagógica alternativa. Os estudantes também reconheceram que as temáticas expostas e debatidas relacionam-se não só à vida em sociedade como à condição existencial humana.
\end{abstract}

Palavras-chave: Ciência, tecnologia e sociedade. Interdisciplinaridade. Educação e literatura. Ficção científica. Cidadania.

Abstract: This study explored the impact of using science fiction associated to socioscientific issues in the moral and reasoning development of students and the consequent awakening to citizenship. We developed and applied a didactic sequence, in a Freirean perspective, based on Brave new world novel, for high school students. The didactic sequence is grounded in the discussion and debates about support material prepared for the following socioscientific issues, highlighted from the novel: consumerism, drug use, genetic manipulation and social exclusion. The didactic intervention was evaluated through a questionnaire. We verified the students developed a critical sense by relating contemporary socioscientific issues to the society created by Aldous Huxley in 1932. The students perceived the activity as interdisciplinary, relating the addressed topics to various disciplines and evaluated the alternative pedagogical practice as positive. The students also recognized these issues are related not only to their life in society but to existential human condition.

Keywords: Science, technology and society. Interdisciplinary. Education and literature. Science fiction. Citizenship education.

\footnotetext{
${ }^{1}$ Universidade do Estado do Rio de Janeiro (UERJ), Instituto de Biologia, Departamento de Ensino de Ciências e Biologia (DECB), Rio de Janeiro, RJ, Brasil. E-mail: <acgoes@uerj.br>.

${ }^{2}$ Centro Federal de Educação Tecnológica Celso Suckow da Fonseca (CEFET), Rio de Janeiro, RJ, Brasil.
} 


\section{Introdução}

\section{Literatura e leitura crítica do mundo}

A literatura constitui um dos fundamentos do sistema da formação linguística, intelectual, cívica e moral dos estudantes, atuando como objeto e ferramenta da educação e ensino, pois está relacionada tanto aos valores, à língua e ao seu aprendizado quanto à manipulação do discurso (FRAISSE, 2012). A reflexão de Fraisse é bastante audaciosa ao afirmar que, nos dias atuais, é impossível dissociar língua, literatura e cultura. Da mesma forma, recomenda-se, no Brasil, que o ensino da língua seja permeado em todas as disciplinas (BRASIL, 1998).

Considera-se que o ato de ler voltado para a construção da cidadania, em contexto interdisciplinar, é essencial para o desenvolvimento de jovens críticos. O leitor se impregna das ficções literárias, as quais exercem o papel de ampliar os horizontes dos indivíduos, aguçando os meios de expressão e despertando o senso crítico. Por outro lado, há obras que exercem função alienadora, pois são desvinculadas de qualquer intenção questionadora (FHILADELFIO, 2003).

Para discutir estas ideias, Fhiladelfio (2003) analisou exemplos fictícios relacionados ao desenvolvimento social, de acordo com a prática específica de leitura (literatura questionadora e literatura de massa ou romance "cor-de-rosa"), de protagonistas femininos dos romances $O$ Quinže e As três Marias, de Rachel de Queiroz. A autora afirma que Rachel de Queiroz não só desempenhou importante papel ao discutir a educação de mulheres no Brasil, como indicou a necessidade de uma condução apropriada de leitura na educação, para a formação de cidadãos críticos. Fhiladelfio (2003) também ressalta que não se trata de impedir os estudantes de acessar os produtos da indústria cultural, mas de capacitá-los, na escola, para perceber a limitação imposta por estas obras, os "enlatados", em relação ao desenvolvimento de uma consciência social crítica.

Em relação à ficção científica, uma importante aplicação desta ferramenta se dá na investigação de caminhos que levem a problematização e investigação cultural ativa por parte dos estudantes, pois uma obra de ficção científica de qualidade é aquela que lança luz sobre as questões vinculadas à Ciência e Tecnologia (C\&T) que afetam nosso modo de vida na sociedade (PIASSI, 2013). Tal visão entra em conformidade com as propostas curriculares para o ensino de Ciências na perspectiva Ciência-Tecnologia-Sociedade (CTS), ao defender o letramento científico dos estudantes de forma que estes possam participar e interagir conscientemente na sociedade. Da mesma forma, Gomes-Maluf e Souza (2008) consideram a produção literária de ficção científica como inspiração para a discussão de temas reais e imaginários.

Eco (1985) considera a ficção científica de forma ainda mais abrangente. Segundo esse autor, a boa ficção científica é interessante não por falar de prodígios tecnológicos, mas porque se propõe como jogo narrativo sobre uma determinada conjecturalidade. Assim, o autor de ficção científica seria um cientista imprudente, o qual, ao conjecturar, por exemplo, sobre fenômenos sociais, prevê e anuncia um mundo possível, como forma de alerta. Imagina-se um futuro inaceitável para que este futuro não se verifique. Eco exemplifica sua lógica através da obra 1984, de George Orwell, afirmando que a narrativa antecipa não para encorajar, mas para alertar as pessoas. Em um ensaio denominado "O texto, o prazer, o consumo", Eco (1985) afirma que na obra 1984 não há nada de original em relação a romances anteriores, como Admirável mundo novo, de Aldous Huxley, de 1932. No entanto, 1984 impõe à sociedade um "pavor mitológico", trazendo à tona terrores individuais, o que atinge drasticamente o imaginário coletivo. De 
acordo com Eco, o que impressiona em 1984 não é que o livro possa ter sido escrito, mas que algo terrível, do mesmo gênero, possa nos acontecer. Isto reforça o potencial desencadeador de reflexões sócio-políticas a partir de obras como 1984 e Admirável mundo novo.

As distopias são excelentes fontes de discussão e reflexão sobre futuros ou realidades indesejáveis para a nossa sociedade. Não à toa, o ano de 2017 iniciou-se, nos Estados Unidos, com uma explosão de vendas das obras distópicas 1984 e Admirável mundo novo. A posse de Donald Trump como presidente do país mais poderoso do mundo parece ter inaugurado uma nova era sombria para a humanidade (ALTARES, 2017). Os leitores estão ávidos para entender, por exemplo, como uma sociedade pode se tornar refém e submissa de um pequeno grupo de pessoas ambiciosas, que exerce um poder esmagador, exatamente como exemplificado nestas obras literárias.

\section{Ensino de Ciências e enfoque CTS: diálogos interdisciplinares}

A abordagem CTS considera a importância em adotar questões sociais relativas a essa temática, associadas ao cotidiano dos estudantes (SANTOS; MORTIMER, 2001). De acordo com esses autores, os professores de Ciências deveriam incorporar às suas aulas discussões sobre temas sociais envolvendo os assuntos relativos à C\&T, como aspectos ambientais, culturais, econômicos, políticos e éticos. Mais especificamente, devem ser estimulados debates relacionados às demandas da sociedade, como os hábitos de consumo, as relações humanas, de trabalho e de valores. Desta forma, podem ser desenvolvidas atividades de engajamento social dos alunos, por meio de discussão dos valores envolvidos e ações concretas (AULER; DELIZOICOV, 2001).

Pinheiro, Silveira e Bazzo (2007) destacaram a importância do enfoque CTS no ensino Médio, ressaltando a relevância da aproximação do aluno com esta temática em todas as dimensões da sociedade, incorporando questões sociais, éticas e políticas. Daí a importância de discutir com os alunos não só os avanços da C\&T, mas principalmente, as causas e consequências deste avanço, assim como os interesses econômicos e políticos envolvidos neste processo, de forma contextualizada (BITTENCOURT; STRUCHINER, 2015).

De acordo com Auler, Dalmolin e Fenalti (2009), o enfoque CTS e os pressupostos do educador Paulo Freire se aproximam por meio da abordagem temática, já que ambos defendem a superação da excessiva fragmentação disciplinar, postulando um trabalho interdisciplinar.

A interdisciplinaridade vem sendo discutida, há bastante tempo, como uma necessidade para o real aprendizado, superando-se a visão fragmentada da produção de conhecimento e privilegiando-se a interação entre os conhecimentos da humanidade. Embora não exista consenso sobre o conceito de interdisciplinaridade, há um desejo em romper as barreiras disciplinares com que as instituições ligadas ao saber estão confinadas (POMBO, 1994). Assim, busca-se o conjunto como forma de reflexão, pois se o que se espera do aluno é a apreensão de fatos sociais relevantes que envolvam aspectos científicos, dificilmente uma disciplina sozinha dará conta deste objeto (RICARDO; ZYLBERSZTAJN, 2008).

Desta forma, práticas de ensino que visem a superação da visão restrita de mundo, utilizando, por exemplo, as potencialidades da discussão de questões sócio-científicas no ensino de Ciências, possibilitam uma visão mais ampla do conhecimento e, consequentemente, favorecem a interação política e social dos estudantes em seu meio (AUGUSTO et al., 2004; GALVÃO; REIS; FREIRE, 2011). 
Ainda, devido à aplicação da Ciência em diversas áreas de trabalho, é viável e aconselhável integrar outras áreas específicas do componente curricular e o cotidiano dos alunos (SANTOS, 2007; SANTOS; MORTIMER, 2009). No contexto escolar brasileiro, a proposta de transversalidade é amplamente estimulada nos Parâmetros Curriculares Nacionais (PCN), fundamentada na crítica à concepção de conhecimento que toma a realidade como um conjunto de dados estáticos (BRASIL, 1998).

Há alguns anos observa-se um movimento no sentido de agrupar propostas curriculares CTS no ensino de Ciências com outras que se fundamentam na formação para a cidadania (AIKENHEAD, 2006; ZEIDLER; NICHOLS, 2009). Esta tendência mais abrangente e interdisciplinar do movimento CTS/ensino de Ciências se relaciona com as ideias humanísticas de Freire, de maneira a suplantar a visão reducionista do enfoque CTS (AULER, 2007). Santos (2008) defende que a proposta da temática CTS na perspectiva humanística Freireana não se restringe ao debate do uso ou não de mecanismos tecnológicos. Busca-se uma educação capaz de refletir sobre a condição existencial humana. Ainda, segundo Santos (2008, p. 122):

Isso significa levar em conta a situação de opressão em que vivemos, a qual é marcada por um desenvolvimento em que valores da dominação, do poder, da exploração estão acima das condições humanas. Nesse sentido, uma educação com enfoque CTS na perspectiva freireana buscaria incorporar ao currículo discussões de valores e reflexões críticas que possibilitem desvelar a condição humana. Não se trata de uma educação contra o uso da tecnologia e nem uma educação para o uso, mas uma educação em que os alunos possam refletir sobre a sua condição no mundo frente aos desafios postos pela ciência e tecnologia.

Este manuscrito visa discutir o impacto da utilização de uma obra de ficção científica em sala de aula, com o intuito de estimular a leitura crítica do mundo, conforme preconizado por Freire. Considerando-se que, no ensino de Ciências, é fundamental a percepção crítica sobre as interações entre Ciência-Tecnologia-Sociedade, desenvolvemos uma dinâmica de trabalho através da busca, na obra Admirável mundo novo, de elementos que exemplificam o condicionamento da sociedade contemporânea aos avanços científico-tecnológicos. O trabalho é considerado interdisciplinar e se justifica pelo próprio conceito CTS, e consequentemente, pela aproximação com as áreas da Sociologia, Filosofia, História, Artes e Literatura. Esperamos contribuir para o desenvolvimento do senso crítico, estimulando a percepção, por parte dos estudantes, das fortes correlações existentes entre a sociedade criada por Huxley em 1932 e a nossa sociedade contemporânea.

\section{O Admirável mundo novo- possibilidades de abordagens do enfoque CTS}

Admirável mundo novo (Brave new world) é uma obra de ficção científica publicada em 1932 pelo inglês Aldous Huxley (1894-1963). Tendo sido lançada antes do início da II Guerra Mundial, a obra já trazia ideias e visões pessimistas sobre os rumos da sociedade. Trata-se de um misto de fantasia e sátira em uma futura sociedade tecnológica. A estabilidade social é o objetivo maior das pessoas que governam o "mundo novo" e, em busca desta tão almejada estabilidade, são utilizadas diversas tecnologias, numa verdadeira revolução científica. 
Nesta obra, as críticas à ciência e à tecnologia (C\&T) são evidentes e o cenário retratado corresponde a uma sociedade organizada por um sistema de castas, obtido graças à manipulação científica de embriões. Não há vontade livre nem mobilidade entre as castas e impera a estabilidade social. Há produção em série do ser humano, de modo que a partir da fecundação de um único óvulo sejam originados 96 gêmeos. Assim, toda a comunidade é padronizada em grupos uniformes, constituídos a partir de um único embrião. Neste sistema, os indivíduos de cada casta compartilham a mesma cultura e pensamento para que o ideal de uniformidade seja garantido.

Os fetos dos indivíduos das castas Gama, Delta e Ipsilon sofrem determinados tratamentos químicos, em um processo denominado Bokanovsky, para que não desenvolvam o intelecto e não alcancem altas estaturas, já que são a mão de obra da sociedade. A comunidade deve estar plenamente satisfeita, a ponto de não haver nenhum dissidente no grupo. Para tal, a população não deve se sentir forçada a nada, amando e aceitando a vida que leva. Na obra, isto é possível a partir de invenções e descobertas científicas por parte dos governantes. Inicialmente, os indivíduos são submetidos a uma técnica de sugestão altamente aperfeiçoada: o condicionamento infantil (processo provavelmente inspirado nos estudos de Pavlov sobre reflexo condicionado, na década de 1920). Nessa etapa, crianças de cada casta são induzidas a simplesmente aceitar sua função na sociedade e os adultos são condicionados com o auxílio de drogas, o Soma (mistura de cocaína, heroína e álcool), cuja utilização não só é permitida como estimulada e indispensável. O objetivo do seu consumo é a não expressão de emoções e a sensação imediata de bem-estar proporcionada aos indivíduos. Nesta sociedade, a família foi abolida, não há espaço para os sentimentos, os quais são vistos como verdadeiras obscenidades.

No texto, há também uma clara referência ao Fordismo, um sistema de produção criado pelo empresário norte-americano Henry Ford em 1914, cuja principal característica é a fabricação em massa. Esse foi o principal sistema de produção durante o século XX, marcado por uma ordem excessiva. Huxley se baseou neste sistema ao imaginar a sociedade do "mundo novo", assim como Charles Chaplin no filme Tempos modernos, de 1936.

Admirável mundo novo é uma obra clássica sobre o domínio, a liberdade e o futuro da espécie humana, que expõe um futuro dominado quase que integralmente pelas técnicas e pelo saber científico manipulados, resultando em uma sociedade absolutamente mecânica, autoritária e desumanizada.

A ideia de que a tecnologia sempre acarreta desenvolvimento econômico ou é útil para a sociedade é apresentada nesta obra de forma implícita e implacável. A obra parece ser um alerta para a sociedade, como analisado por Eco (1985), um aviso de que a tecnologia não deve ser aceita como conhecimento superior, imposta pelos tecnocratas. O cidadão deveria participar das decisões sobre C\&T, questionando a ideologia dominante e imposta à sociedade como fator desenvolvimentista.

Huxley (1987, p. 16) afirma no prefácio de seu livro que:

As pessoas que governam o Admirável Mundo Novo podem não ser sensatas...; mas não são loucas, e seu fim não é a anarquia, e sim, a estabilidade social. É para realizar a estabilidade social que levam a cabo, por meios científicos, a última e pessoal revolução realmente revolucionária.

Ao orientarmos os jovens educandos a ler e comparar a sociedade atual em relação às "previsões" feitas por Huxley em sua obra (CLEMENTE et al., 2011; SANTOS; AMORIM 
Góes, A. C. S. et al.

NETO; GÓES, 2013), estimulamos a reflexão dos alunos sobre questões que afetam a sociedade, principalmente no âmbito CTS, contribuindo para a educação para a cidadania.

\section{Fundamentação e abordagem metodológica}

Para o desenvolvimento deste trabalho, consideramos que a aproximação com temas sociais, no ensino de Ciências, não pode ser realizada através da simples inserção destes temas no currículo. De acordo com Santos e Mortimer (2000), deve haver uma mudança significativa nas concepções pedagógicas relacionadas a esta temática. Desta forma, investimos em estratégias de ensino inovadoras, que levem em consideração a contextualização e interação com diversas disciplinas para o sucesso no processo ensino-aprendizagem (FAZENDA, 2005; ZABALA, 1998). Ao mesmo tempo, Cachapuz (1999) aponta o enfoque CTS como orientação para a educação em Ciências, afirmando que esta prática não deve se limitar à construção e repetição de conceitos. O ponto de partida para a aprendizagem, segundo Cachapuz, deveria se constituir da apresentação de "situações-problema". A partir destes pressupostos, elaboramos uma intervenção didática, baseada na obra Admirável mundo novo, com o intuito de apresentar, para os alunos de ensino Médio, situações-problema provenientes do contexto fictício desta obra literária.

A intervenção é constituída de uma sequência didática (ZABALA, 1998) fundamentada na abordagem de temas CTS em uma perspectiva freireana, já que os alunos são apresentados a temas de trabalho, a partir de situações problema, e são estimulados a discutir e debater os temas de forma a desenvolver uma visão humanística e crítica da realidade (FREIRE, 1987).

De acordo com Freire, a educação é instrumento para o "despertar" do indivíduo e consequente superação das condições sociais vigentes. Para cumprir esta função, a educação deve ser problematizadora e de caráter reflexivo. Foram abordados os seguintes temas CTS (situações-problema), por nós destacados, da obra: (1) consumismo, (2) uso de drogas, (3) manipulação genética, e (4) exclusão social (CLEMENTE et al., 2011). Ainda baseado em pressupostos freireanos, estes temas foram destacados por serem constituídos de contradições presentes na dinâmica social.

As atividades foram aplicadas em uma turma de terceiro ano do ensino Médio com 33 alunos, entre 16 e 19 anos, de um colégio público e técnico do Estado do Rio de Janeiro, em quatro tempos de aula (50 minutos cada) da disciplina Biologia. A primeira aula (2 tempos) foi iniciada com a apresentação do vídeo $A$ história das coisas visando a motivação inicial para a introdução dos temas de trabalho, especialmente o relacionado ao consumismo. O documentário $A$ história das coisas (The story of stuff), que foi produzido em 2007 pela ativista ambiental norte-americana Annie Leonard, tem duração de 21 minutos. A abordagem apresentada no vídeo enfatiza a linha de produção dos bens de consumo, desde a extração da matéria-prima até o momento da venda nas prateleiras dos estabelecimentos comerciais e o estímulo ao consumismo, fazendo uma relação direta entre as etapas da produção e o descarte dos produtos. Este documentário foi correlacionado, mais adiante, com a sociedade de consumo do Mundo Novo.

Posteriormente à projeção, os alunos foram convidados a participar ativamente de um breve debate sobre as questões abordadas no vídeo, durante o qual foram incentivados a expor as suas opiniões sobre a sociedade de consumo do século XXI. Em seguida, uma apresentação foi exibida aos alunos, expondo a sinopse da obra Admirável mundo novo, juntamente com a biografia do autor. 
Para iniciar as discussões que dão sequência às atividades e finalizam o primeiro dia de trabalho com a obra, os alunos se organizaram em quatro grupos e receberam o material de apoio produzido pela nossa equipe, contendo trechos selecionados do livro, figuras e tirinhas, canções e reportagens que se relacionam com os temas selecionados. De posse dos materiais de apoio, os alunos discutiram em seus grupos as temáticas propostas, acompanhados por membros da equipe desta pesquisa. A segunda aula (2 tempos) ocorreu uma semana após a primeira. Foram apresentadas duas canções ("Admirável gado novo", composta por Zé Ramalho em 1980 e "Admirável chip novo", de Pitty em 2006) como motivação inicial e foi retomada a discussão iniciada na primeira aula. Os alunos, organizados em grupos, continuaram a leitura e o debate sobre os temas contidos no material distribuído na aula anterior.

Após o debate, os alunos apresentaram oralmente um resumo do que foi discutido em seus grupos, nos temas selecionados, fazendo uma espécie de relato à turma. Neste momento, a formação da turma em grupos de alunos foi desfeita para dar espaço a um debate coletivo. Durante a apresentação, cada aluno contribuiu pessoalmente, formando uma rede de saberes e opiniões sobre os temas propostos pelo professor e debatidos em grupo na etapa anterior.

\section{Coleta e avaliação de dados}

Esta pesquisa é qualitativa, pois objetivou a análise de um determinado fenômeno (o processo de utilização de literatura de ficção científica nas aulas) e a percepção dos estudantes em relação a este fenômeno (a relação entre o que foi apresentado e a vida em sociedade, a formação para a cidadania, a relação entre os temas CTS abordados, as disciplinas escolares e a atualidade dos temas selecionados).

A coleta de dados foi realizada individualmente com os alunos, por meio da aplicação de um questionário, para uma pesquisa de opinião acerca da intervenção, caracterizando um estudo de campo (GIL, 2002). Também foi solicitado aos alunos uma redação individual sobre o tema debatido em grupo. Os dados foram analisados utilizando-se a interpretação qualitativa dos questionários e das redações produzidas pelos alunos, buscando a identificação clara dos sentidos, valores, opiniões e do posicionamento dos indivíduos. Frases ou palavras que expressavam o mesmo sentido foram agrupadas em categorias (FONTOURA, 2011; MINAYO, 2012). Os alunos foram identificados através de códigos (A1, A2, ...).

\section{Análise do impacto da intervenção}

Neste manuscrito, analisamos o impacto de uma intervenção didática, para o ensino médio, baseada na obra Admirável mundo novo. Com esta proposta, pretendemos verificar se houve a percepção, por parte dos alunos, da relação entre a obra e a temática CTS. Os alunos foram estimulados através do debate de questões éticas e sócio-políticas que afetam a nossa sociedade, com o objetivo de promover a leitura crítica de mundo e consequente formação para a cidadania. O trabalho foi realizado em torno dos quatro temas por nós destacados da obra: consumismo, uso de drogas, manipulação genética e exclusão social. Os resultados descritos a seguir foram obtidos a partir da tabulação dos dados dos questionários e redações individuais. 


\section{Sequência didática interdisciplinar baseada em obra literária}

Inicialmente, foi perguntado aos alunos se, antes da aplicação desta sequência didática, eles haviam tido alguma aula que abordasse os temas propostos neste trabalho. De maneira geral, os alunos afirmaram já terem tido contato com os temas abordados nesta pesquisa através de diferentes disciplinas, assim como por meio de palestras e internet. O caráter interdisciplinar desta proposta pedagógica torna-se evidente ao observamos que, segundo os alunos, os temas trabalhados neste projeto já haviam sido abordados nas aulas de Geografia, História, Sociologia, Filosofia, Literatura, Português, Psicologia, Ciências, Biologia, Ética e Cidadania, Química e História da Arte.

Desta forma, verificamos que, ao trabalharmos com a obra de ficção científica Admirável mundo novo, introduzimos uma vertente curricular alternativa, que se aproxima de temas sociais relacionados à matriz científico-tecnológica, conforme postulado por alguns autores (AULER, DALMOLIN; FENALTI, 2009; SANTOS; MORTIMER, 2000). Ou seja, a partir da literatura, fomentamos oportunidades de questionamentos a respeito não apenas de fenômenos científicos, mas, da própria natureza da atividade científica e de sua relação com a sociedade. Assim, o ensino de temas sócio-científicos, através da prática de debates, pode contribuir na educação para a cidadania (KACEM; SIMONNEAUX, 2009). Zeidler e Nichols (2009) constatam que temas sociocientíficos são importantes ferramentas para engajar os estudantes no diálogo, discussão e debate, conforme executado nesta prática pedagógica. Além de serem temas controversos, por natureza, estes requerem, dos estudantes, discernimento moral e ético para participar de processos decisórios na sociedade. No entanto, um dos alunos fez o seguinte comentário sobre a atividade por nós desenvolvida: "Ótimo projeto, que impulsiona ao bábito da leitura e do estudo em áreas diversificadas, apesar da evasiva aos temas diretamente ligados à biologia" [A5].

Através do depoimento do aluno A5, observamos uma crítica à atividade “interdisciplinar", demonstrando a falta de familiaridade do mesmo com este tipo de aula e a não percepção de que os conteúdos da disciplina Biologia podem ser abordados através de tópicos temáticos e controversos, de forma transversal.

Entre os 33 alunos participantes da pesquisa, somente um havia lido a obra Admirável mundo novo e 27 disseram que se motivaram a ler o livro a partir da abordagem desta prática didática. Três alunos afirmaram já terem lido as seguintes obras de ficção científica: Eu robô, de Isaac Asimov, O Imortal, de Machado de Assis, e Viagem ao Centro da Terra, de Julio Verne. Vinte e dois alunos afirmaram que gostariam que fossem utilizados outros livros de ficção científica nas próximas aulas de Biologia, tendo um aluno sugerido a obra $A$ ilha, de Aldous Huxley.

De fato, a proposta de correlacionar as culturas científica e humanística (CACHAPUZ; PRAIA; JORGE, 2004) tem sido desenvolvida em trabalhos que propõem a aproximação entre a Ciência e a literatura no ensino de Ciências. Por exemplo, Groto e Martins (2015) analisaram os limites e as possibilidades da utilização das obras $A$ reforma da natureza e serões de dona Benta, de Monteiro Lobato, em aulas de Ciências. Salomão (2008) estudou o papel potencializador da literatura na aprendizagem de Ciências através da peça de teatro Lição de botânica, de Machado de Assis.

Piassi (2015) fundamenta as razões para a utilização da ficção científica na educação em Ciências em função de suas potencialidades problematizadoras, pois ela cria conflitos que podem desencadear o questionamento crítico. O autor também comenta que a literatura de 
ficção científica pode ser uma excelente ferramenta para se articular o conhecimento da Ciência às possibilidades presentes e futuras da vida e da cultura humanas, como fizemos neste trabalho com a obra Admirável mundo novo. Ao analisar romances de ficção científica do autor Arthur Clarke, Piassi (2011) afirma que o uso de obras literárias poderia auxiliar na abertura e reflexão sobre um sistema de valores e preocupações humanas mais abrangentes, que motivem e estimulem o estudante a perceber sua significação cultural.

Neste sentido, os romances distópicos modernos adaptados para o cinema, como Jogos vorazes, também apresentam forte potencial para o desenvolvimento de trabalhos, com os estudantes (SILVA et al., 2016). A partir de um dos temas por nós também abordados, a manipulação genética, Knippels, Severiens e Klop (2009) introduziram temas sociocientíficos em sala de aula, utilizando como ferramenta a ficção em clips de filmes futurísticos. O grupo avaliou esta estratégia como estimuladora de habilidades, como o raciocínio crítico.

Enfim, de uma forma mais abrangente, Cachapuz $(2013,2014)$ aponta as possíveis abordagens no ensino das Ciências através de uma perspectiva interdisciplinar que envolva o diálogo entre arte e Ciência. Foucault (2001) analisa a arte na sociedade moderna como mensageira de um discurso trágico, negativo e radical, desencadeadora de mudanças, polemizadora e crítica da ordem presente, a qual aponta novos caminhos para reflexão.

Assim, neste trabalho, propusemos a associação do enfoque CTS com a literatura para o estímulo de reflexões de cunho sócio-culturais subjacentes a estes temas. Consideramos que a apresentação, aos estudantes, e estímulo à leitura de ficções distópicas como Admirável mundo novo, 1984, Fahrenheit 451, entre outros clássicos, teria o papel de desenvolver o pensamento crítico.

Os alunos mostram ter noção desta dimensão da ficção científica, além de perceberem a relação entre a obra Admirável mundo novo, escrita em 1932, e a sociedade contemporânea, conforme os relatos listados:

\footnotetext{
Apesar dos temas serem atualmente impostos em nossa sociedade, a visão do autor seria uma visão "teórica" de como seria o mundo em seu futuro. [A23].

Como os assuntos foram abordados de um livro de 1932 algumas coisas "batem" no que acontece hoje. [A31].

Por mais que o livro seja antigo, aborda muitos temas atuais que nos vivemos no dia-adia. [AG].
}

Verificamos que, através deste exemplo de intervenção pedagógica, levantamos discussões focadas em temas relevantes para a Ciência tratados na obra, como a metodologia científica, o comportamento humano e os diversos questionamentos que afligem a humanidade e que se fazem atuais na sociedade contemporânea. Enfim, é possível discutir temas CTS atuais, relacionados à cidadania e ao cotidiano dos alunos.

O professor dificilmente encontrará apoio para a abordagem destes temas em livros didáticos, já que os temas não se limitam a uma única disciplina e sim a um contexto interdisciplinar. Desta forma, a proposta pedagógica apresentada neste manuscrito consiste em um material alternativo e inovador, que pode ser fonte de inspiração para o trabalho destes professores. Estes contribuiriam para a formação do aluno-cidadão ao levá-los a refletir sobre os aspectos morais 
e éticos da aplicação do conhecimento científico, em um contexto interdisciplinar, tendo como base a leitura e a discussão de um clássico da literatura de ficção científica mundial.

A sequência didática proposta neste artigo pode ser reproduzível pelos professores com as devidas adaptações em relação à atualização das reportagens. Ainda, o estilo de roteiro pode ser mantido para a abordagem de outros temas atuais e relevantes tratados na obra, como Ciência e qualidade de vida, saúde e sociedade, manutenção da estabilidade social, Ciência e arte, mídia e sociedade, movimentos fascistas e eugenia, entre outros. Em um contexto de trabalho efetivamente interdisciplinar, as aulas podem ser ministradas simultaneamente por professores de diversas disciplinas (FARIAS et al., 2017). A abordagem interdisciplinar da obra Admirável mundo novo poderia se dar entre os professores de Biologia (metodologias e técnicas científicas, como a manipulação genética), de Língua Portuguesa (contextualização da obra como um grande clássico da literatura mundial), de História (ascensão de movimentos fascistas) e de Sociologia (processos para o alcance da estabilidade e alienação na sociedade).

Quando solicitados a opinar sobre as aulas e debates em torno da obra Admirável mundo novo, os alunos se expressaram com palavras que foram agrupadas em três categorias principais: "inovação", "excelência" e "reflexão".

Estes dados mostram que é possível desenvolver o senso crítico e a consequente formação para a cidadania através de práticas escolares alternativas, que proporcionem um contexto interdisciplinar e cultural. A abertura da escola e dos professores perante assuntos de interesse social dos alunos deve fazer parte do processo educacional, considerando-se, principalmente, que a leitura é ingrediente imprescindível na formação de um sujeito crítico (CURIA, 2012). Assim, constatamos que a introdução, em salas de aula, de tópicos da Ciência contemporânea, revelados através da literatura, como um produto cultural determinado sócio-historicamente, é crucial para o desenvolvimento intelectual e social dos alunos.

\section{Desenvolvimento do raciocínio crítico: reflexões sobre a sociedade e o enfoque CTS através da obra Admirável mundo novo}

De acordo com Auler (2007), ao refletir sobre a aproximação entre o enfoque CTS e os pressupostos de Freire, o movimento CTS postula a superação do modelo de decisões tecnocráticas em relação a temas sociais. Já Freire (1987), de forma ainda mais abrangente, enfatiza a necessidade da superação da "cultura do silêncio" para se desenvolver uma sociedade democrática. Neste momento, um vínculo imediato se faz entre estas duas ideias e a obra Admirável mundo novo. O Mundo Novo é dominado pelas técnicas e pelo saber científico, a sociedade é composta de cidadãos "robôs", os quais foram criados a partir de metodologias de manipulação genética. Estes cidadãos não exercem a democracia na sociedade em que vivem. Nesta sociedade, impera o desperdício e consumo desmesurados, incentivo ao uso de drogas e alienação política.

Assim, a proposta pedagógica utilizando a obra Admirável mundo novo como modelo de sociedade oprimida pelos avanços científico-tecnológicos, foi capaz de levar os alunos a refletir sobre a sua própria participação democrática na sociedade atual. A nossa experiência corrobora estudos que mostram como a sensibilidade aos aspectos morais e éticos da sociedade pode ser aprimorada através de práticas relacionadas ao ensino de Ciências com ênfase em temas sóciocientíficos (FOWLER; ZEIDLER; SADLER, 2009; LEE et al., 2013). 
A maioria dos alunos (mais de 90\%) considerou que os assuntos abordados durante a aplicação do projeto são relacionados à vida deles em sociedade. Abaixo estão listadas algumas frases citadas pelos alunos, que refletem o estímulo à leitura crítica de mundo após os debates em sala de aula:

Assuntos da cobrança governamental na sociedade. [A2].

Nossa politica de hoje em dia. [A17].

A respeito da subdivisão da sociedade e até que ponto a ciência pode influenciar nessa questão. [A19].

Através dos relatos citados acima, principalmente o do aluno A19, podemos verificar o "despertar" dos estudantes para assumir uma posição crítica diante da predestinação/exclusão social vigente no mundo contemporâneo, que cresce em função dos avanços científico-tecnológicos. Já o depoimento abaixo exprime uma reflexão sócio-política mais precisa: " $A$ ideia de "bondade" em relação aos planos de governo da presidente Dilma foi mudada em algumas pessoas" [A14].

Assim, esperamos ter trabalhado com a proposta CTS que enfoca o desenvolvimento de valores, os quais estão vinculados a interesses coletivos, como o de solidariedade, de consciência do compromisso social e de respeito ao próximo (SANTOS, 2007). Por exemplo, o aluno afirma que: “... devemos ver melhor nossos conceitos em relação a sociedade, nossas atitudes dentro dela e formas de julgarmos cada pessoa" [A30].

A perspectiva de CTS crítica objetiva a problematização de temas sociais, de modo a incentivar o engajamento social dos alunos. Desta forma, a proposta pedagógica explorou as dimensões sociais nas quais os fenômenos destacados da obra literária estão inseridos na sociedade contemporânea. Em propostas semelhantes prioriza-se a reflexão sobre as condições sociais subjacentes à situações-problema. Por exemplo, não se foca no ensino de nomes científicos de agentes infecciosos e processos de desenvolvimento de doenças, mas nos fatores sociais que determinam a proliferação de microorganismos, causadores de doenças, em determinadas comunidades (GRYNSZPAN et al., 2013). Da mesma forma, atividades que explorem aspectos críticos relacionados à ideia de temas antiéticos proporcionam a discussão sobre a natureza da Ciência e a forma como evolui a construção deste conhecimento (ANGOTTI; AUTH, 2001).

Quando questionados sobre a impressão causada por esta proposta didática, a maioria dos alunos (mais de 90\%) se expressou positivamente, considerando atuais os temas abordados e inclusive relacionados à problemática sócio-cultural brasileira. Alguns exemplos de como justificaram as suas respostas estão listados a seguir:

Por mais que o livro seja antigo, aborda muitos temas atuais que nós vivemos no dia-adia. [A16].

São temas que estão em desenvolvimento na atualidade e estão ao nosso redor. [A28].

É algo que podemos ver na sociedade atual através do consumismo, mídia e exclusão social. [A1]. 
Atualmente vivemos em uma sociedade bem consumista e a exclusão existe também, temas que temos que refletir mais. [A4].

Assim, observa-se que os alunos perceberam a relação e a aproximação entre a vida deles em sociedade, temas do conteúdo curricular e um clássico da literatura mundial. Os depoimentos mostram que o impacto causado por esta intervenção se relaciona ao entrecruzamento das questões levantadas na obra com as próprias questões agudas do modo de vida juvenil.

A abordagem e discussão, principalmente dos temas predestinação e exclusão social e consumismo, destacados da obra, nos ofereceu a oportunidade de trabalhar o ensino de Ciências através das interações CTS para além das implicações sociais. De acordo com Santos (2008), o ensino CTS à luz da perspectiva freireana busca a transformação do modelo racional de C\&T excludente para um modelo voltado para a justiça e igualdade social. Os depoimentos dos alunos A1 e A4 acima parecem indicar a percepção, após a intervenção com a prática pedagógica, de injustiça e desigualdade na sociedade contemporânea.

O desenvolvimento de valores, como objetivo do movimento CTS, se relaciona às necessidades humanas. Entre elas, destaca-se a perspectiva de questionamento à ordem capitalista, na qual os valores econômicos se impõem aos demais (SANTOS, 2007). Esta é exatamente a reflexão realizada por um estudante:

\begin{abstract}
Achei interessante como o livro fez alusão ao consumismo de forma tão forte, como se ele fosse (e como ultimamente ele é) super importante para que a economia cresça e o estado se desenvolva e assim possa melhorar a qualidade de vida das pessoas o que na minha opinião não é uma verdade já que os consumidores não tem essa qualidade no seu dia-a-dia. [A30].
\end{abstract}

Enfim, os alunos percebem, na obra Admirável mundo novo, elementos fictícios que exemplificam problemáticas de dimensão social contemporânea: "O projeto desenvolvido em minha turma me levou a pensar sobre coisas que estavam presentes em minha vida e que não tinha refletido ainda". [A17].

Principalmente, os estudantes se conscientizam que uma sociedade constituída de cidadãos críticos seria um fator de impedimento para o desenvolvimento das práticas anti-democráticas e opressoras do Mundo Novo. Em relação às críticas e sugestões dos alunos quanto a esta prática pedagógica, destacamos a seguinte frase, agrupada para a categoria "importância":

O projeto desenvolvido na turma teve imensa importancia para o desenvolvimento crítico de muitos alunos em relação a estrutura da sociedade que nos encontramos. Essa ideia de "certo ou errado", benéfico ou não gerou a capacidade de criticar as ideias abordadas no livro e em nossa vida no dia a dia. [A5, grifo nosso].

Para a categoria "reflexão", destacamos as seguintes frases:

Achei boas e construtivas para se pensar no mundo em que vivemos. [A10, grifo nosso].

O projeto é muito bom, pois nos faz refletir sobre a sociedade atual, os erros, acertos, o que poderíamos fazerer para melhorar a situação. [A31, grifo nosso]. 
Os depoimentos indicam que intervenções deste tipo são bem-vindas entre os estudantes. Porém, de acordo com Santos (2007), professores de Ciências em geral não se sentem a vontade para promover debates em torno de questões políticas. Desta forma, muitas vezes a abordagem da temática CTS se restringe a apresentação de aplicações tecnológicas. Por outro lado, as expectativas de jovens estudantes nas escolas consistem, entre outras, em professores que ministrem aulas de forma menos tradicional, que não sejam meros transmissores de conteúdos, e que as escolas "preparem para a vida" (LEÃO; DAYRELL; REIS, 2011).

Entre os pontos destacados pelos alunos como positivos em nossa proposta, estão a oportunidade de interação entre eles para discutir os temas de trabalho e o fato destes temas terem sido desenvolvidos por eles e não pelo professor.

Em alguns casos, o que a escola oferece não é atrativo para os alunos, pois estes não conseguem atribuir sentido. Os estudantes demandam maior diálogo das disciplinas com a realidade cotidiana (DAYRELL; JESUS, 2016). Os nossos dados reforçam estas afirmações, indicando o desejo dos alunos em se preparar para o exercício da cidadania, conforme destacado: "Acho necessário, esse tipo de aula para os jovens, futuros adultos que serão o futuro da nação" [A28].

\section{Considerações finais}

Neste manuscrito, discutimos a aplicação de uma prática pedagógica, baseada na obra Admirável mundo novo, a qual é um terreno fértil para trabalhar o enfoque CTS associado a um embasamento humanístico/freireano. A obra descreve um exemplo de sociedade oprimida, organizada em seres trabalhadores, pertencentes a diferentes castas, as quais são desenvolvidas pela tecnologia da engenharia genética.

Verificamos que a análise, com os alunos, de temas levantados a partir desta obra pode suscitar a reflexão, entre outros, sobre o processo de exclusão social observado no Brasil e em países periféricos do Terceiro Mundo. Certo, os avanços tecnológicos nos trazem uma melhora na qualidade e expectativa de vida, por meio de, por exemplo, medicamentos, métodos diagnósticos e vacinas da infância à terceira idade. Mas, o que dizer de uma enorme parcela da população que permanece na marginalidade, embora tenha acesso a iphones e equipamentos de última geração? Observa-se a exploração ambiental e a divisão não equiparada de lucros. Ao mesmo tempo, tornase evidente que as necessidades de funcionamento do sistema definem as "falsas necessidades" de consumo ao invés de as necessidades humanas determinarem as necessidades de produção.

Os depoimentos dos alunos apontam para um despertar crítico. Concluímos que o contato com a obra Admirável mundo novo, para além de estimular discussões sobre a temática CTS, desencadeou, nestes estudantes, uma série de reflexões sobre a condição humana frente aos desafios atuais impostos pela C\&T.

Ao desenvolver um mecanismo de compreensão e difusão de direitos e práticas sociais constituído de um instrumento de intervenção com enfoque CTS associado à literatura, contribuímos com uma educação científica comprometida com a formação-cidadã. A análise dos resultados indica que os debates, devidamente precedidos por estímulos, como a apresentação da obra literária e o contexto histórico mundial em que Admirável mundo novo se insere, assim como a descoberta da relação entre as célebres canções e a obra, estimularam a reflexão dos alunos sobre as questões éticas e políticas que envolvem a sociedade. 
A leitura/literatura foi trabalhada de forma dialógica no ensino de Ciências, contribuindo para o desenvolvimento de competências necessárias ao exercício participativo da cidadania. Com esta prática, também tentamos estabelecer um paralelo com a proposta educacional de Freire, que além de ser dialógica e baseada em temas, postulava a liberdade através da transformação do contexto alienador e opressor da sociedade brasileira. Alienação e opressão são as palavras-chave de Admirável mundo novo.

Espera-se acima de tudo que, ao compreender como Ciência, Tecnologia e Sociedade encontram-se inter-relacionadas, os alunos sejam capazes de utilizar seus conhecimentos de forma integrada na solução de problemas cotidianos, derrubando as barreiras disciplinares escolares nas suas vivências em sociedade.

Por fim, vale destacar que, assim como C\&T, arte e sociedade são indissociáveis, sendo a arte entendida como reflexo da realidade social. Ao propor aos estudantes a análise da obra Admirável mundo novo, estimulamos a percepção da interação Ciência-Tecnologia-Sociedade a partir de um universo ainda mais abrangente.

\section{Agradecimentos}

À Fundação Carlos Chagas Filho de Amparo à Pesquisa do Estado do Rio de Janeiro (E26/110.802/2011).

\section{Referências}

AIKENHEAD, G. S. Science education for everyday life: evidence-based practice. New York: Teachers College Press, 2006.

ALTARES, G. “1984” lidera as vendas de livros nos EUA desde a posse de Trump. E1

País, Madrid, 26 jan. 2017. Disponível em: <http://brasil.elpais.com/brasil/2017/01/26/ cultura/1485423697_413624.html>. Acesso em: 21 mar. 2017.

ANGOTTI, J. A. P.; AUTH, M. A. Ciência e tecnologia: implicações sociais e o papel da educação. Ciência \& Educação, Bauru, v. 7, n. 1, p.15- 27, 2001. Disponível em: <https:// doi.org/10.1590/S1516-73132001000100002>. Acesso em: 8 ago. 2018.

AUGUSTO, T. G. S. et al. Interdisciplinaridade: concepções de professores da área ciências da natureza em formação em serviço. Ciência \& Educação, Bauru, v. 10, n. 2, p. 277-289, 2004. Disponível em: <https://doi.org/10.1590/S1516-73132004000200009>. Acesso em: 8 ago. 2018.

AULER, D. Articulação entre pressupostos do educador Paulo Freire e do movimento CTS: novos caminhos para a educação em ciências. Revista Contexto \& Educação, Ijuí, v. 22, n. 77, p. 167-188, 2007. Disponível em: <https://doi.org/10.21527/2179-1309.2007.77.167188>. Acesso em: 8 ago. 2018. 
AULER, D.; DALMOLIN, A. M. T.; FENALTI, V. S. Abordagem temática: natureza dos temas em Freire e no enfoque CTS. Alexandria: revista de educação em ciência e tecnologia, Florianópolis, v. 2, n. 1, p. 67-84, 2009. Disponível em: <https://periodicos.ufsc. br/index.php/alexandria/article/view/37915>. Acesso em: 8 ago. 2018.

AULER, D.; DELIZOICOV, D. Alfabetização científico-tecnológica para quê? Ensaio: pesquisa em educação em ciências, Belo Horizonte, v. 3, n. 1, p. 105-115, 2001.

BITTENCOURT, L. P.; STRUCHINER, M. A articulação da temática da doação de sangue e o ensino de biologia no ensino médio: uma pesquisa baseada em design.

Ciência \& Educação, Bauru, v. 21, n.1, p. 159-176, 2015. Disponível em: < https://doi. org/10.1590/1516-731320150010011>. Acesso em: 8 ago. 2018.

BRASIL. Ministério da Educação. Secretaria de Educação Fundamental. Parâmetros curriculares nacionais: ciências naturais $3^{\circ}$ e $4^{\circ}$ ciclos. Brasília, 1998.

CACHAPUZ, A. F. Art and science: improving teachers' interdisciplinary competences. Journal of Science Education, Bogotá, v. 14, special issue, p. 7-11, 2013.

CACHAPUZ, A. F. Arte e ciência no ensino das ciências. Interacções, Lisboa, v. 10, n. 31, p. 95-106, 2014. (Número especial).

CACHAPUZ, A. F. Epistemologia e ensino das ciências no pós-mudança conceptual: análise de um percurso de pesquisa. In: ENCONTRO NACIONAL DE PESQUISA EM ENSINO DE CIÊNCIAS, 2., 1999, Valinhos. Atas... Disponível em: < http://fep.if.usp.br/ profis/ arquivos/iienpec/Dados/trabalhos/A02.pdf>. Acesso em: 8 ago. 2018.

CACHAPUZ, A. F.; PRAIA, J.; JORGE, M. Da educação em ciência às orientações para o ensino das ciências: um repensar epistemológico. Ciência \& Educação, Bauru, v. 10, n. 3 , p. 363-381, 2004. Disponível em: <https://doi.org/10.1590/S1516-73132004000300005>. Acesso em: 8 ago. 2018.

CLEMENTE, A. C. et al. A utilização da literatura de ficção científica como recurso didático: um ensaio sobre a obra Admirável mundo novo. In: ENCONTRO NACIONAL DE PESQUISA EM ENSINO DE CIÊNCIAS, 8., 2011, Campinas. Atas... Disponível em: <http://www.nutes.ufrj.br/abrapec/viiienpec/resumos/R1405-1.pdf>. Acesso em: 8 ago. 2018.

CURIA, D.F.S. A Literatura infanto-juvenil na contemporaneidade: um outro olhar para o literário em sala de aula. Revista Thema, Pelotas, v. 9, n. 2, p. 1-17, 2012.

DAYRELL, J. T.; JESUS, R. E. Juventude, ensino médio e os processos de exclusão escolar. Educação \& Sociedade, Campinas, v. 37, n. 135, p. 407-423, 2016. Disponível em: <https://doi.org/10.1590/ES0101-73302016151533>. Acesso em: 8 ago. 2018.

ECO, U. Os mundos da ficção científica. In: ECO, U. Sobre os espelhos e outros ensaios. São Paulo: Difel, 1985. p. 200-208.

ECO, U. O texto, o prazer, o consumo. In: ECO, U. Sobre os espelhos e outros ensaios. São Paulo: Difel, 1985. p. 121-132. 
Góes, A. C. S. et al.

FARIAS, J. M. N. et al. Linhagem mitocondrial e os personagens do romance O tempo e o vento: a interdisciplinaridade representada em material didático. Experiências em Ensino de Ciências, Cuiabá, v. 12, n. 2, p. 24-37, 2017.

FAZENDA, I. C.A. Interdisciplinaridade: definição, projeto, pesquisa. In: FAZENDA, I. C. A. Práticas interdisciplinares na escola. 10. ed. São Paulo: Cortez, 2005. p 15-18.

FHILADELFIO, J. A. Literatura, indústria cultural e formação humana. Cadernos de Pesquisa, São Paulo, v. 120, p. 203-219, 2003. Disponível em: <http://dx.doi.org/10.1590/ S0100-15742003000300010>. Acesso em: 8 ago. 2018.

FONTOURA, H. A. Tematização como proposta de análise de dados na pesquisa qualitativa. In: FOUNTOURA, H. A. Formação de professores e diversidades culturais: múltiplos olhares em pesquisa. Niterói: Intertexto, 2011. p. 61-82.

FOUCAULT, M. Estética: literatura e pintura, música e cinema. São Paulo: Forense Universitária, 2001.

FOWLER, S. R.; ZEIDLER, D. L.; SADLER, T. D. Moral sensitivity in the context of socioscientific issues in high school science students.International Journal of Science Education, London, v. 31, n. 2, p. 279-296, 2009.

FRAISSE, E. L'enseignement de la littérature: un monde à explorer. Revue Internationale d'Éducation de Sèvres, Sèvres, n. 61, p. 35-45, 2012. Disponível em: < https:/ /journals. openedition.org/ries/2664>. Acesso em: 8 ago. 2018.

FREIRE, P. Pedagogia do oprimido. 17. ed. Rio de Janeiro: Paz e Terra, 1987.

GALVÃO, C.; REIS, P.; FREIRE, S. A discussão de controvérsias sociocientíficas na formação de professores. Ciência \& Educação, Bauru, v. 17, n. 3, p. 505-522, 2011. Disponível em: <https://doi.org/10.1590/S1516-73132011000300001>. Acesso em: 8 ago. 2018.

GIL, A.C. Como elaborar projetos de pesquisa. 4. ed. São Paulo: Atlas, 2002.

GOMES-MALUF, M. C.; SOUZA, A. R. A ficção científica e o ensino de ciências: o imaginário como formador do real e do racional. Ciência \& Educação, Bauru, v. 14, n. 2, p. 271-282, 2008. Disponível em: <http://dx.doi.org/10.1590/S1516-73132008000200006>. Acesso em: 8 ago. 2018.

GROTO, S. R.; MARTINS, A. F. Monteiro Lobato em aulas de ciências: aproximando ciência e literatura na educação científica. Ciência \& Educação, Bauru, v. 21, n. 1, p. 219-238, 2015. Disponível em: < https://doi.org/10.1590/1516-731320150010014>. Acesso em: 8 ago. 2018.

GRYNSZPAN, D. et al. Educação em saúde e educação ambiental: uma experiência inovadora com base em uma perspectiva socioambiental ligada à promoção da saúde. In: IX CONGRESO INTERNACIONAL SOBRE INVESTIGACIÓN EN DIDÁCTICA DE LAS CIENCIAS, 9., 2013, Girona. Anais... Disponível em: < https://www.raco.cat/index. php/Ensenanza/article/viewFile/307417/397391>. Acesso em: 8 ago. 2018. 
A obra Admirável mundo novo no ensino interdisciplinar: ...

HUXLEY, A. Admirável mundo novo. São Paulo: Victor Civita, 1982.

HUXLEY, A. Regresso ao admirável mundo novo. São Paulo: Círculo do Livro, 1987.

KACEM, S.; SIMONNEAUX, L. The teaching of socioscientific issues in interdisciplinarity biology-philosophy, an ethical stake and citizenship issue. US-China Education Review, Valley Cottage, v. 6, n. 2, p. 44-47, 2009.

KNIPPELS, M. P. J.; SEVERIENS, S. E.; KLOP, T. Education through fiction: acquiring opinion-forming skills in the context of genomics. International Journal of Science Education, London, v. 31, n. 15, p. 2057-2083, 2009.

LEÃO, G.; DAYRELL, J. T.; REIS, J. B. Jovens olhares sobre a escola do ensino médio. Caderno Cedes, Campinas, v. 31, n. 84, p. 253-273, 2011. Disponível em: < https://doi. org/10.1590/S0101-32622011000200006>. Acesso em: 8 ago. 2018.

LEE, H. et al. Socioscientific issues as a vehicle for promoting character and values for global citizens. International Journal of Science Education, London, v. 35, n. 12, p. 2079-2113, 2013.

MINAYO, M. C. S. Análise qualitativa: teoria, passos e fidedignidade. Ciência \& Saúde Coletiva, Rio de Janeiro, v. 17, n. 3, p. 621-626, 2012. Disponível em: <https://doi. org/10.1590/S1413-81232012000300007>. Acesso em: 8 ago. 2018.

PIASSI, L.P. A ficção científica como elemento de problematização na educação em ciências. Ciência \& Educação, Bauru, v. 21, n. 3, p. 783-798, 2015. Disponível em: < https://doi. org/10.1590/1516-731320150030016>. Acesso em: 8 ago. 2018.

PIASSI, L. P. A ficção científica e o estranhamento cognitivo no ensino de ciências: estudos críticos e propostas de sala de aula. Ciência \& Educação, Bauru, v. 19, n. 1, p. 151-168, 2013. Disponível em: <https://doi.org/10.1590/S1516-73132013000100011>. Acesso em: 8 ago. 2018.

PIASSI, L. P. A perspectiva sociocultural da física nos romances de ficção científica de Arthur Clarke. Revista Brasileira de Pesquisa em Educação em Ciências, Belo Horizonte, v. 11, n. 2, p. 205-226, 2011.

PINHEIRO, N. A. M.; SILVEIRA, R. M. C. F.; BAZZO, W. A. Ciência, tecnologia e sociedade: a relevância do enfoque CTS para o contexto do ensino médio. Ciência $\boldsymbol{\&}$ Educação, Bauru, v. 13, n. 1, p. 71-84, 2007. Disponível em: < https://doi.org/10.1590/ S1516-73132007000100005>. Acesso em: 8 ago. 2018.

POMBO, O. Problemas e perspetivas da interdisciplinaridade. Revista de Educação, Lisboa, n. 1 /2, p. 3-11, 1994.

RICARDO, E. C.; ZYLBERSZTAJN, A. Os parâmetros curriculares nacionais para as ciências do ensino médio: uma análise a partir da visão de seus elaboradores. Investigações em Ensino de Ciências, Porto Alegre, v. 13, n. 3, p. 257-274, 2008. 
Góes, A. C. S. et al.

SALOMÃO, S. R. Lições de botânica: o texto literário no ensino de ciências. Ciência em

Tela, Rio de Janeiro, v. 1, n. 1, p. 1-9, 2008. Disponível em: <http://www.cienciaemtela. nutes.ufrj.br/artigos/Salomao_2008_1.pdf>. Acesso em: 8 ago. 2018.

SANTOS, W. L. P. Contextualização no ensino de ciências por meio de temas CTS em uma perspectiva crítica. Ciência \& Ensino, Campinas, v. 1, n. esp., p. 1-12, 2007.

SANTOS, W. L. P. Educação científica humanística em uma perspectiva freireana: resgatando a função do ensino de CTS. Alexandria: revista de educação em ciência e tecnologia, Florianópolis, v. 1, n. 1, p. 109-131, 2008.

SANTOS, W. L. P.; MORTIMER, E. F. Abordagem de aspectos sociocientíficos em aulas de ciências: possibilidades e limitações. Investigações em Ensino de Ciências, Porto Alegre, v. 14, n. 2, p. 191-218, 2009.

SANTOS, W. L. P.; MORTIMER, E. F. Uma análise de pressupostos teóricos da abordagem C-T-S (Ciência-Tecnologia-Sociedade) no contexto da educação brasileira. Ensaio: pesquisa em educação em ciências, Belo Horizonte, v. 2, n. 2, p. 133-162, 2000. Disponível em: <https:/ /doi.org/10.1590/1983-21172000020202>. Acesso em: 8 ago. 2018.

SANTOS, W. L. P.; MORTIMER, E. F. Tomada de decisão para ação social responsável no ensino de ciências. Ciência \& Educação, Bauru, v. 7, n. 1, p. 95-111, 2001. Disponível em: <https:/ /doi.org/10.1590/S1516-73132001000100007>. Acesso em: 8 ago. 2018.

SANTOS, A. C. C.; AMORIM NETO, T. P.; GÓES, A. C. S. Ficção científica e o Admirável mundo novo: previsões concretizadas no atual século e considerações bioéticas. História,

Ciências e Saúde - Manguinhos, Rio de Janeiro, v. 20, n. 2, p. 653-673, 2013.

SILVA, L. G. M. et al. Ciência na rádio: incentivando a leitura, a escrita e a reflexão crítica no ensino de biologia. RevistAleph, Rio de Janeiro, v. 13, n. 26, p. 67-78, 2016.

ZABALA, A. A prática educativa: como ensinar. Porto Alegre: Artes Médicas Sul, 1998.

ZEIDLER, D. L.; NICHOLS, B. H. Socioscientific issues: theory and practice. Journal of

Elementary Science Education, Basel, v. 21, n. 2, p. 49-58, 2009.

Artigo recebido em 20/09/2017. Aceito em 25/02/2018.

Contato: Universidade do Estado do Rio de Janeiro, Rua São Francisco Xavier, 524, Maracanã, 22280-030, Rio de Janeiro RJ, Brasil. 